\title{
Stability of a hydraulic telescopic cylinder subjected to generalised load by a force directed towards the positive pole
}

\author{
Sebastian Uzny ${ }^{1}$, and Lukasz Kutrowski ${ }^{1{ }^{1 *}}$ \\ ${ }^{1}$ Institute of Mechanics and Machine Design Fundamentals, Czestochowa University of \\ Technology, Dabrowskiego 73, 42-201 Czestochowa, Poland
}

\begin{abstract}
The paper presents the boundary problem of the stability of a telescopic hydraulic cylinder subjected to a generalized load with a force directed to the positive pole. The boundary problem was formulated on the basis of the Hamilton principle. Numerical calculations were carried out, taking into account the influence of the parameters of the load heads (radii of loading and receiving head, length of bolt). On the basis of the numerical calculations, regions of load heads parameters were presented, at which the load bearing capacity of the analysed telescopic hydraulic cylinder is the largest from the buckling standpoint.
\end{abstract}

\section{Introduction}

Hydraulic cylinders are certain types of engines in which the energy of the hydraulic fluid is converted into the mechanical energy of the translational movement. Apart from hydraulic systems, pneumatic and electric actuators are also used. Hydraulic cylinders are characterized by a greater working force. For this reason, they are successfully used in drives of individual members of construction machines, braking systems or presses with high pressure forces. Hydraulic cylinders can be classified due to many criteria. Due to the number of cylinder stages, one-stage and multistage cylinders can be distinguished. Multistage cylinders are also called telescopic cylinders.

As a result of the use of a larger number of cylinder members, an exceptionally long output travel from a very compact retracted length can be achieved. Hydraulic telescopic cylinders are mainly used in lifting systems of semi-trailers of trucks, drives of working members in basket lifts and elevators with hydraulic drives.

Hydraulic cylinders can be damaged due to many reasons. One of the common failures is the failure of hydraulic seals associated with damage to the cylinders or the piston rod of the actuator. When working in various types of constructions, the actuators can be also exposed to adverse vibrations, which can significantly reduce the service life of the cylinders. Due to the large slenderness of the cylinders, and especially telescopic structures, the basic problem during their design is the buckling phenomenon.

\footnotetext{
${ }^{*}$ Corresponding author: kutrowski@imipkm.pcz.pl
} 
The stability analysis of single-stage hydraulic cylinders were considered in many publications, including [1-8]. Paper [1] presents a mathematical and physical model of a mining support, the construction of which corresponds to a single-stage hydraulic actuator. The results of numerical calculations and experimental tests related to the stability of a single-stage hydraulic cylinder are presented in [2]. Paper [3] presents a theoretical model of a single-stage hydraulic cylinder, taking into account a number of parameters affecting its stability. In publication [4] the effect of inaccuracies between the members of a singlestage cylinder on its stability were considered. The results of numerical and experimental tests were presented. The stability and effort of cylinder material of a single-stage hydraulic cylinder was the subject of work [5]. The flexural rigidity asymmetry factor was defined, and the regions of this parameter were presented with reference to the cylinder and piston rod of the actuator, in which the system is damaged as a result of buckling and effort of the cylinder material. The influence of stiffness increase in the supports of the single-stage actuator on its stability is presented in the publication [6]. The stiffness model of the hydraulic cylinder, which takes into account: axial piston rod deformation, cylinder volumetric expansion, finite stiffness of the supply lines, elasticity of the hydraulic medium, presence of air bubbles in the hydraulic fluid and deformability of the sealing elements are presented in [7]. The comparison of the results of numerical calculations obtained using FEM and the recommendations contained in DNV GL were presented in work [8].

The stability of the hydraulic telescopic cylinder subjected to Euler's load was considered in works [9, 10]. The publication [9] presents the influence of the elastic connection between the following cylinder elements on its stability. In the calculations Lame's theory for thick pipes was taken into account and the ranges of the cylinder barrel thickness parameter were determined, in which the destruction of the system is caused by the loss of stability and the effort of the cylinder material. Work [10] covers the effort analysis of a telescopic hydraulic cylinder. For a series of permissible stresses of the cylinder material, the influence of the cylinder barrel thickness parameter and the seal elements thickness parameter on the strength of individual cylinder barrels is presented. In correlation with buckling curves, the parameter ranges are defined in which the system is destroyed as a result of buckling or as a result of the effort of the material - which cause destruction within the weakest member of the actuator.

Generalized load with force directed to the positive pole was formulated by Tomski and belongs to the group of specific loads [11-14]. This load is caused by external force, directed to the fixed point (pole), which is located on the undeformed axis of the system. In addition, this pole is below the loaded end of the system (cf. fig. 1). The implementation of this load can be carried out in two ways: with the use of linear elements or circular elements. In this work, the case of this load is considered via circular elements.

\section{Boundary problem}

The considered system - a telescopic hydraulic cylinder subjected to a compressive generalized load with a force directed to the positive pole is shown in fig 1 . This system consists of $n$ elements, where elements from 1 to $(n-1)$ are cylinders, and element $n$ is the piston rod. In this system, it is assumed that the stiffness between following cylinder members is infinite. Each cylinder member is characterized by flexural rigidity $(E I)_{i}$, mass per length $(\rho A)_{i}$. In addition, fluid mass per length $(\rho A)_{c i}$ which fills the cylinders is taken into account (in the case of piston $\operatorname{rod}(\rho A)_{c n}=0$ ). The dimensions of each of the cylinder members depend on the diameter of the piston rod and the thickness of the cylinder barrels and sealing elements. In the work, subsequent diameters of the members are calculated using the following formulas: 


$$
\begin{aligned}
& d_{z i}=d_{t}+2(n-i) g_{U}+2(n-i) g_{R} \\
& d_{w i}=d_{t}+2(n-i) g_{U}+2(n-1) g_{R}
\end{aligned}
$$

where $g_{U}$ i $g_{R}$ are thicknesses of seals and cylinder barrels.

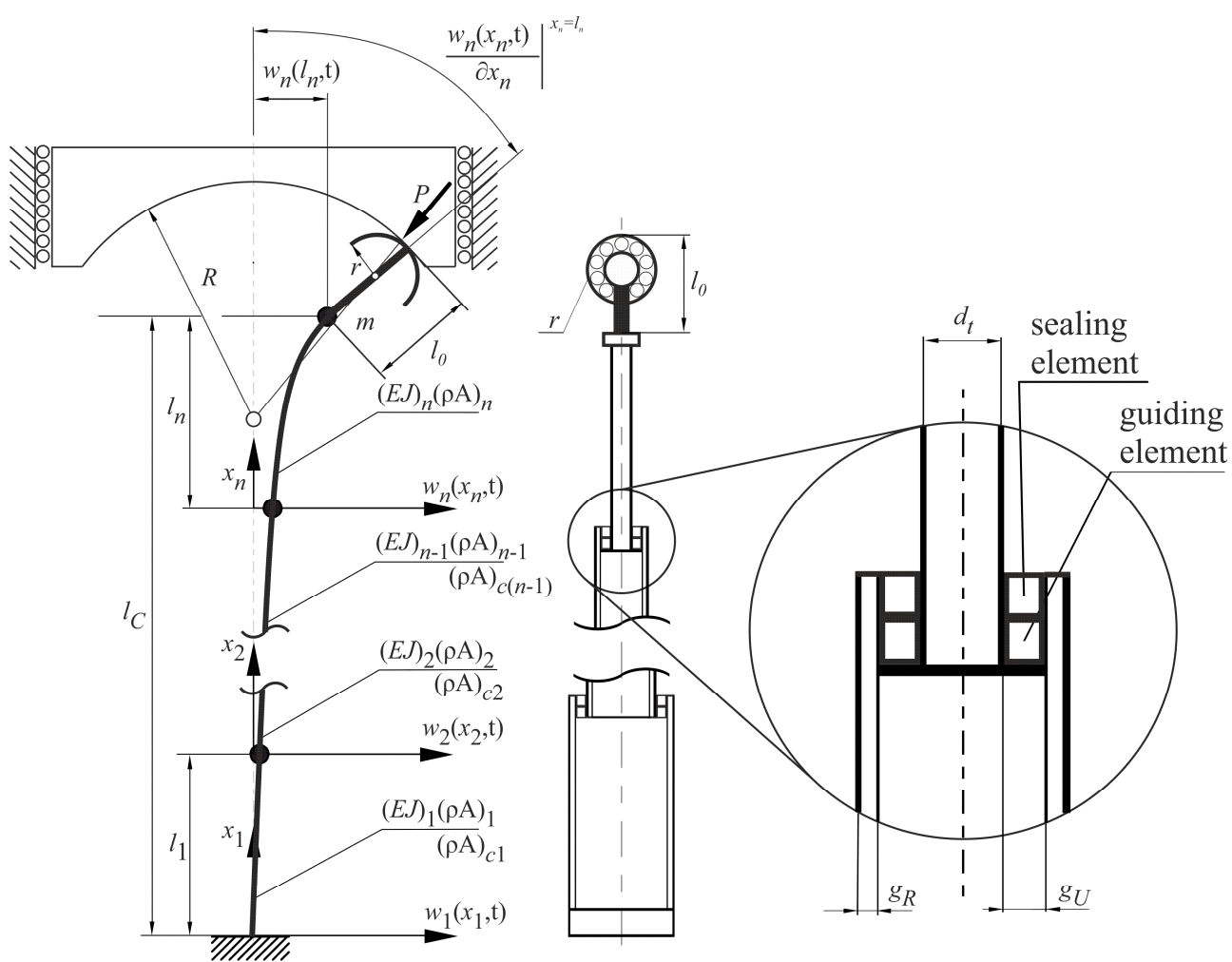

Fig. 1. Scheme of a hydraulic telescopic cylinder subjected to generalized load by a force directed towards the positive pole.

In this work, the critical load of the system is determined using the kinetic stability criterion. The boundary problem of free vibrations was formulated based on the Hamilton principle, taking into account the model of transverse vibrations of the cylinder proposed by Tomski [1]:

$$
\delta \int_{t 1}^{t 2}(T-V) d t=0
$$

Potential energy $V$ and kinetic energy $T$ can be written as follows:

$$
\begin{gathered}
V=\frac{1}{2} \sum_{i=1}^{n} \int_{0}^{l_{i}}(E J)_{i}\left(\frac{\partial^{2} w_{i}\left(x_{i}, t\right)}{\partial x_{i}^{2}}\right)^{2} d x_{i}-\frac{1}{2} P \sum_{i=1}^{n} \int_{0}^{l_{i}}\left(\frac{\partial w_{i}\left(x_{i}, t\right)}{\partial x_{i}}\right)^{2} d x_{i}+ \\
+\frac{1}{2} \frac{P\left(l_{0}-r\right)}{R-r}\left(\frac{w_{n}\left(l_{n}, t\right)}{l_{0}-r}+\left.\frac{\partial w_{n}\left(x_{n}, t\right)}{\partial x_{n}}\right|^{x_{n}=l_{n}}+w_{n}\left(l_{n}, t\right)+\left.\frac{\partial w_{n}\left(x_{n}, t\right)}{\partial x_{n}}\right|^{x_{n}=l_{n}} \frac{\left(r-l_{0}\right)(R-r)}{l_{0}-r}\right)
\end{gathered}
$$




$$
\begin{gathered}
T=\frac{1}{2} \sum_{i=1}^{n}(\rho A)_{i} \int_{0}^{l_{i}}\left(\frac{\partial w_{i}\left(x_{i}, t\right)}{\partial t}\right)^{2} d x_{i}+\frac{1}{2} \sum_{i=1}^{n-1}(\rho A)_{c i} \int_{0}^{l_{l}}\left(\frac{\partial w_{i}\left(x_{i}, t\right)}{\partial t}\right)^{2} d x_{i}+ \\
+\frac{1}{2} m\left(\left.\frac{\partial w_{n}\left(x_{n}, t\right)}{\partial t}\right|^{x_{n}=l_{n}}\right)^{2}
\end{gathered}
$$

After appropriate mathematical transformations, equations of motion and natural boundary conditions can be obtained. After separation of variables, the equations can be written in the form:

$$
\begin{gathered}
(E I)_{i} \frac{d^{4} y_{i}\left(x_{i}\right)}{d x_{i}{ }^{4}}+P \frac{d^{2} y_{i}\left(x_{i}\right)}{d x_{i}^{2}}-(\rho A)_{i} \omega^{2} \frac{d^{2} y_{i}\left(x_{i}\right)}{d x_{i}^{2}}+ \\
-(\rho A)_{c i} \omega^{2} \frac{d^{2} y_{i}\left(x_{i}\right)}{d x_{i}^{2}}=0 \quad \text { for } i=1,2 \ldots n \\
\left.(E I)_{i} \frac{\partial^{3} y_{i}\left(x_{i}\right)}{\partial x_{i}^{3}}\right|^{x_{i} l_{i}}-\left.(E I)_{i+1} \frac{\partial^{3} y_{i+1}\left(x_{i+1}\right)}{\partial x_{i+1}{ }^{3}}\right|_{x_{i+1}=0}+\left.P \frac{\partial y_{i}\left(x_{i}\right)}{\partial x_{i}}\right|^{x_{i}=l_{i}}-\left.P \frac{\partial y_{i+1}\left(x_{i+1}\right)}{\partial x_{i+1}}\right|_{x_{i+1}=0}=0 \\
-\left.(E I)_{i} \frac{\partial^{2} y_{i}\left(x_{i}\right)}{\partial x_{i}^{2}}\right|^{x_{i}=l_{i}}+\left.(E I)_{i+1} \frac{\partial^{2} y_{i+1}\left(x_{i+1}\right)}{\partial x_{i+1}{ }^{2}}\right|_{x_{i+1}=0}=0 \\
\left.(E I)_{n} \frac{\partial^{3} y_{n}\left(x_{n}\right.}{\partial x_{n}{ }^{3}}\right|^{x_{n}=l_{n}}+P\left(\frac{r-l_{0}}{R-r}\right)\left(\left.\frac{\partial y_{n}\left(x_{n}\right)}{\partial x_{n}}\right|^{x_{n}=l_{n}}\left(R-l_{0}\right)-y_{n}\left(l_{n}\right)\right)=0 \\
\left.(E I)_{n} \frac{\partial^{3} y_{n}\left(x_{n}\right)}{\partial x_{n}{ }^{3}}\right|^{x_{n}=l_{n}}+P\left(\frac{1}{R-r}\right)\left(\left.\frac{\partial y_{n}\left(x_{n}\right)}{\partial x_{n}}\right|^{x_{n}=l_{n}}\left(R-l_{0}\right)-y_{n}\left(l_{n}\right)\right)+m \omega^{2} y_{n}\left(l_{n}\right)=0
\end{gathered}
$$

In the analysed system, the geometrical boundary conditions are distinguished:

$$
\begin{gathered}
y_{i}\left(l_{i}\right)=y_{i+1}(0) \\
\left.\frac{\partial y_{i}\left(x_{i}\right)}{\partial x_{i}}\right|^{x_{i}=l_{i}}=\left.\frac{\partial y_{i+1}\left(x_{i+1}\right)}{\partial x_{i+1}}\right|_{x_{i+1}=0} \\
y_{1}(0)=0 ;\left.\frac{d y_{1}\left(x_{1}\right)}{d x_{1}}\right|_{x=0}=0
\end{gathered}
$$

The solution of equations of motion is presented in form:

$$
y_{i}\left(x_{i}\right)=A_{i} \cosh \left(\alpha_{i} x_{i}\right)+B_{i} \sinh \left(\alpha_{i} x_{i}\right)+C_{i} \cos \left(\beta_{i} x_{i}\right)+D_{i} \sin \left(\beta_{i} x_{i}\right)
$$

where:

$$
\begin{gathered}
\alpha_{i}=\sqrt{-\frac{k_{i}^{2}}{2}+\sqrt{\frac{k_{i}^{4}}{4}+\Omega_{i}{ }^{2}}} ; \beta_{i}=\sqrt{\frac{k_{i}^{2}}{2}+\sqrt{\frac{k_{i}^{4}}{4}+\Omega_{i}{ }^{2}}} \\
\Omega_{i}{ }^{2}=\frac{\left((\rho A)_{i}+(\rho A)_{c i}\right) \omega^{2}}{(E I)_{i}} ; k_{i}{ }^{2}=\frac{P}{(E I)_{i}}
\end{gathered}
$$

Taking into account the equations (6-14) in the solution (15), the system of equations is obtained. The matrix determinant of coefficients equated to zero leads to the transcendental equation, from which the natural vibration frequency can be obtained. The critical load of the analysed system corresponds to the first natural frequency equal to zero. 


\section{Results of numerical simulations}

Results of numerical calculations are presented by using non-dimensional parameters:

$$
\zeta_{G U}=\frac{g_{U}}{d_{t}} ; \zeta_{G R}=\frac{g_{R}}{d_{t}} ; \zeta_{L}=\frac{l_{C}}{d_{t}} ; \lambda_{c r}=\frac{P_{c r} l_{C}^{2}}{(E I)_{n}} ; \zeta_{l 0}=\frac{l_{0}}{R} ; \zeta_{R}=\frac{R}{l_{C}} ; \zeta_{r}=\frac{r}{R}
$$

where:

$\zeta_{G U}$ - parameter of sealing and guiding elements thickness

$\zeta_{G R}$ - parameter of cylinder barrel thickness

$\zeta_{L}$ - parameter of cylinder length

$\lambda_{c r}$ - parameter of critical load

$\zeta_{l 0}$ - parameter of bolt length

$\zeta_{R}-$ parameter of loading head radius

$\zeta_{r}$ - parameter of receiving head radius

Fig. 2-5 shows the effect of three dimensionless parameters of load heads $\left(\zeta_{l 0}, \zeta_{R}, \zeta_{r}\right)$ on the stability of a telescopic hydraulic cylinder with three and five stages.

Based on the results presented in fig. 2-3, it was noticed that the ratio of the radius of the receiving head to the radius of the head inducing the load of the system (the relationship represented by parameter $\zeta_{r}$ ) has a significant impact on the critical load. In the range of this parameter $\langle 0.6 ; 0.9\rangle$, the critical load increases when the $\zeta_{R}$ parameter is increased (at lower values). At higher values of the parameter $\zeta_{R}$ the critical load of the system decreases with increasing this parameter. In the case when the parameter $\zeta_{r}$ is lower than or equal to $0.5-$ the increase of the radius of the loading head (increase of the parameter $\zeta_{R}$ ) causes a significant decrease of the load capacity of the system. The trend of curves changes $\lambda_{c r}\left(\zeta_{R}\right)$ is the same for a three and five stages cylinder.

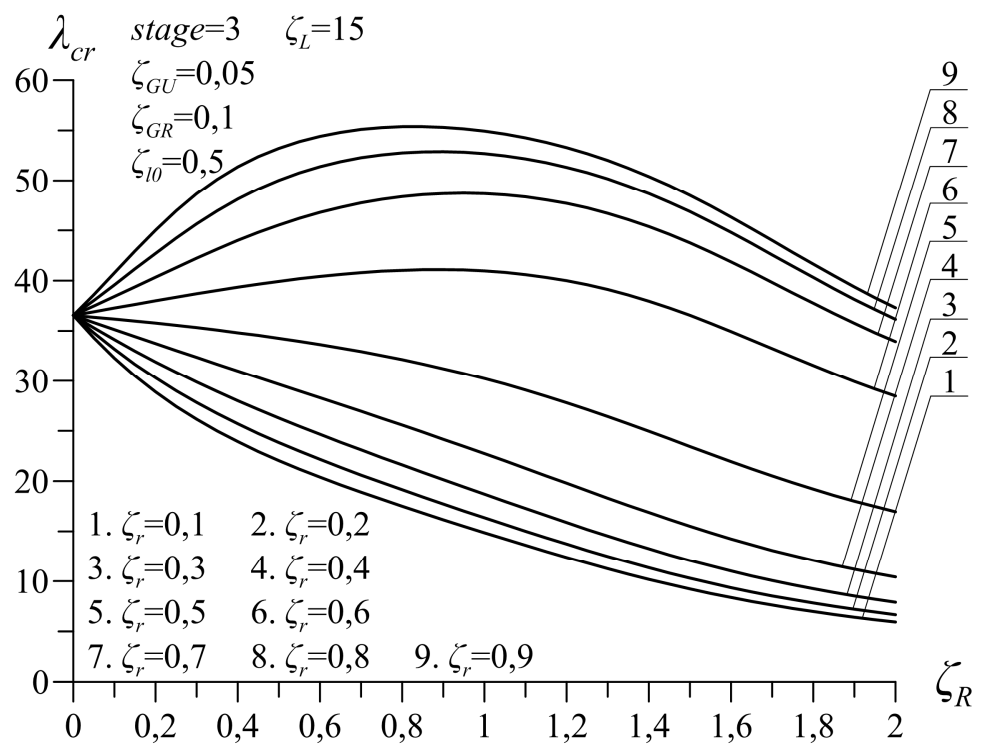

Fig. 2. The influence of parameter $\zeta_{R}$ (for different parameters $\zeta_{r}$ ) on stability of three stages hydraulic cylinder. 


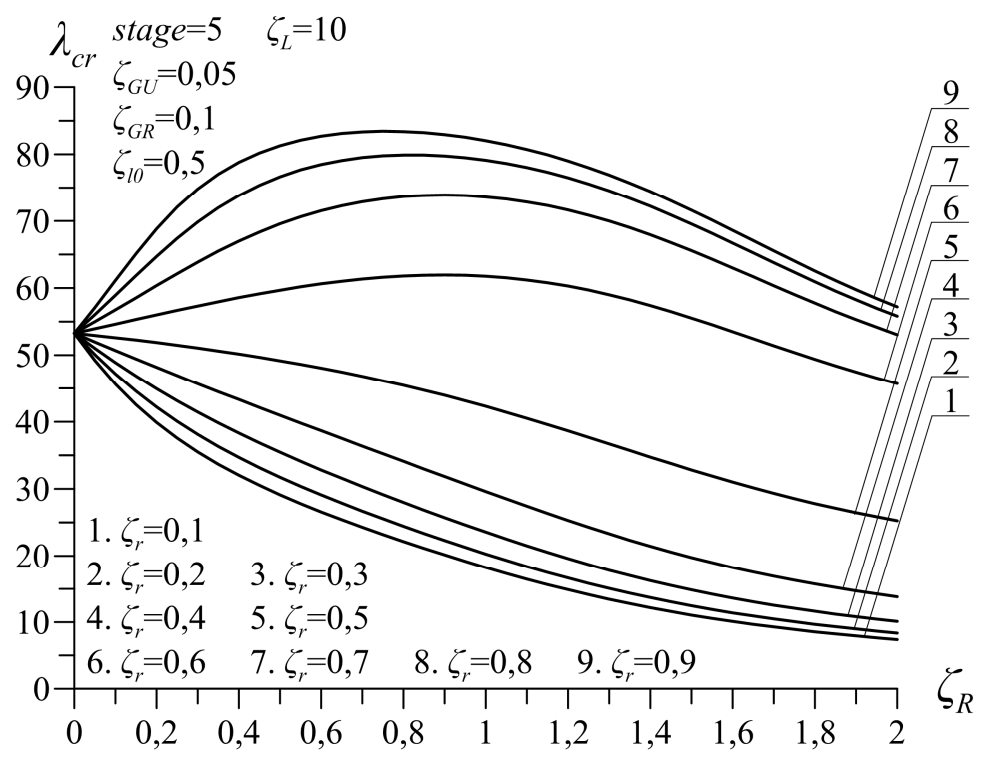

Fig. 3. The influence of parameter $\zeta_{R}$ (for different parameters $\zeta_{r}$ ) on stability of five stages hydraulic cylinder.

The influence of the bolt length on the structural stability is shown in fig. 4-5. It was shown that with the assumed system parameters in the case when the parameter $\zeta_{l 0}$ is from the interval $\langle 0 ; 0,6\rangle$, the critical load of the system is increasing when the radius of the loading head is increased in a certain range. The greater the length of the bolt, the higher the critical load increase is. Increasing the length of the bolt (from the range $\zeta_{l 0} \in\langle 0 ; 0,6\rangle$ ) the maximum critical load occurs at higher radius of the loading head. Increasing the length of the bolt while increasing the radii of the load heads causes a decrease in the critical load.

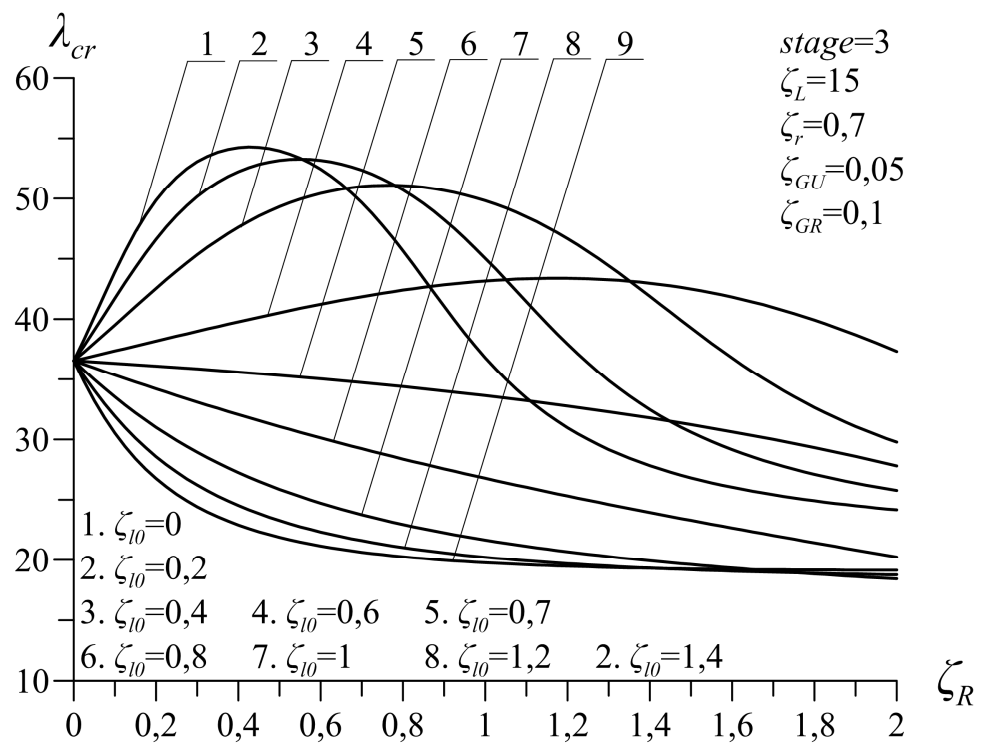

Fig. 4. The influence of parameter $\zeta_{R}$ (for different parameters $\zeta_{l 0}$ ) on stability of three stages hydraulic cylinder. 


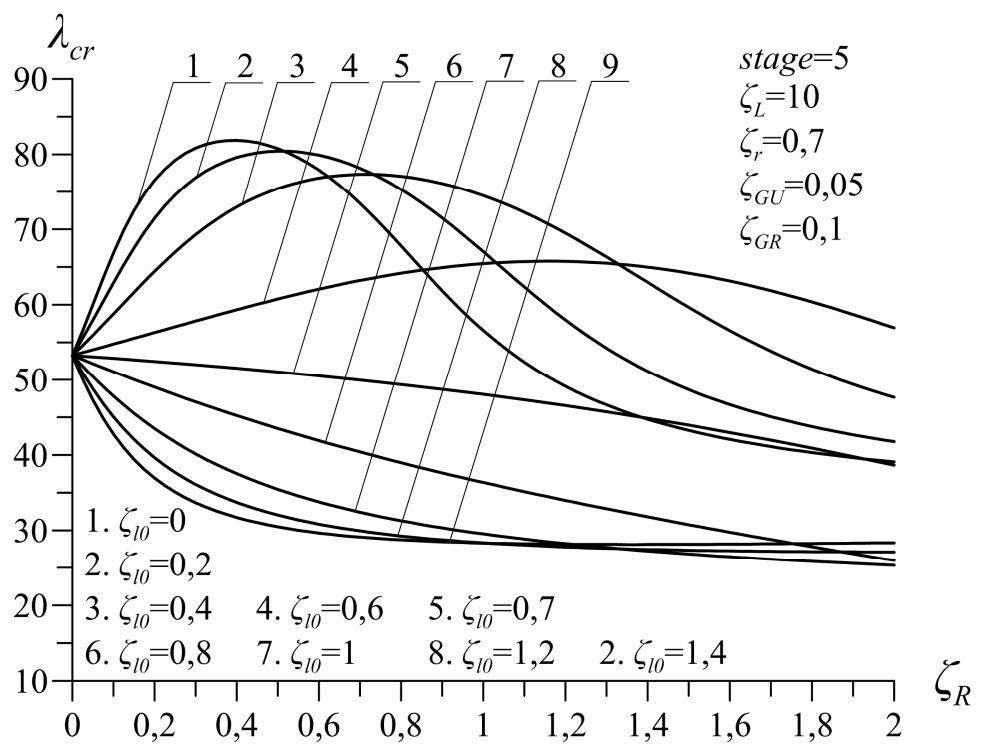

Fig. 5. The influence of parameter $\zeta_{R}$ (for different parameters $\zeta_{l 0}$ ) on stability of five stages hydraulic cylinder.

\section{Conclusions}

This paper presents the stability problem of a telescopic hydraulic cylinder subjected to a generalized load with a force directed towards to the positive pole. The boundary problem was formulated using the kinetic criterion of stability. The equations of motion and boundary conditions of the considered system are presented. With specific assumptions regarding the thickness of cylinders and seals, numerical simulations were carried out regarding the critical load of the system depending on the parameters of the load heads. Based on the obtained critical load distributions, the intervals of the parameters of the load heads, at which the considered system is characterized by the highest load capacity, can be determined. As a continuation of the research, the impact of the parameters of the load heads implementing the load considered in this work should be determined on the characteristic curves determined on the plane of load - natural frequency.

The study has been carried out within the statutory funds of the Czestochowa University of Technology (BS/PB 1-101-3020/17/P).

\section{References}

1. L. Tomski, Engineering Transactions. 25(2). 247-263 (1977)

2. L. Tomski, S. Uzny, Zeszyty Naukowe Politechniki Rzeszowskiej. seria: Mechanika. 258(74). 369-380 (2008)

3. V. Gómez Rodríguez, J. Jose Cabello Eras, H. Hernández Herrera, R. Goytisolo, IJET. 8(6). 2443-2451 (2016/2017)

4. P.J. Gamez-Montero, E. Salazar, R. Castilla, J. Freire, M. Khamashta, E. Codina, IJMS, 51(2), 105-113 (2009) 
5. L. Tomski, S. Uzny, ACME, 11(3), 769-785 (2011)

6. S. Uzny, Proc. Appl. Math. Mech., 9, 303-304 (2009)

7. F. Hao, D. Qungui, H. Yuxian, Ch. Yongbin, STROJ VESTN-J MECH E., 63(7-8), 447-456 (2017)

8. E. Narvydas, Mechanika, 22(6), 474-477 (2016)

9. S. Uzny, K. Sokół, Ł. Kutrowski, In: Rusiński E., Pietrusiak D. (eds). Proceedings of the 13th International Scientific Conference. Lecture Notes in Mechanical Engineering. Springer, 581-588 (2017)

10. S. Uzny, Ł. Kutrowski, Modelowanie Inżynierskie, 68 , 125-131 (2019)

11. L. Tomski, Drgania i stateczność układów smuktych, Warszawa: WNT (2004)

12. L. Tomski, Drgania swobodne i stateczność obiektów smuktych jako układów liniowych lub nieliniowych, Warszawa: WNT (2007)

13. L. Tomski, Drgania swobodne i stateczność układów smukłych poddanych obciązeniu konserwatywnemu lub niekonserwatywnemu, Warszawa: PWN (2012)

14. L. Tomski, J. Szmidla, J THEOR APP MECH-POL, 42(1), 163-193 (2004) 